\title{
Re-examination of Capsule Development and Lectin-binding Sites on Rhizobium japonicum 3I1B110 by the Glutaraldehyde/Ruthenium Red/ Uranyl Acetate Staining Method
}

\author{
By J. M. VASSE,' F. B. DAZZO² AND G. L. TRUCHET ${ }^{1 *}$ \\ 1 Institut de Cytologie et de Biologie Cellulaire, LA 179, Faculté des Sciences Marseille Luminy. \\ 13288 Marseille Cedex 9, 13288 France \\ 2 Department of Microbiology and Public Health, Michigan State University, East Lansing. \\ Michigan 48824, USA
}

(Received 7 February 1984)

\begin{abstract}
Capsular development and soybean lectin binding properties of Rhizobium japonicum 3I1B110 were examined by the glutaraldehyde/ruthenium red/uranyl acetate method permitting observation of whole bacteria and their polar capsules by transmission electron microscopy. Ultrastructurally, the polar capsule consisted of (i) an electron-dense aggregated material in close contact with the cell surface which stained with ruthenium red and intensively bound soybean lectin, and (ii) a less electron-dense fibrillar material at the periphery of the capsule which stained with ruthenium red but did not bind soybean lectin. The latter material interconnected with the aggregated capsular material at the cell surface. As the culture advanced into stationary phase, these acidic capsular materials were shed into the culture medium where they kept their respective lectin-binding activity. The cells correspondingly decreased in their lectin-binding activity and encapsulation with culture age. However, the remaining encapsulated cells in late stationary phase were still able to bind the lectin in a hapten-specific way.
\end{abstract}

\section{INTRODUCTION}

According to the lectin-recognition hypothesis (Bohlool \& Schmidt, 1974), the specificity in a Rhizobium-legume symbiosis involves the interaction between host lectins and bacterial polysaccharides. Soybean lectin (SBL) binds specifically to the majority of $R$. japonicum strains grown in broth (Bal et al., 1978; Bhuvaneswari \& Bauer, 1978; Bhuvaneswari et al., 1977; Bohlool \& Schmidt, 1974; Kamberger, 1979; Shantharam et al., 1980; Stacey et al., 1980; Tsien \& Schmidt, 1981), but also binds to several heterologous strains of the cowpea miscellany group (Bhuvaneswari \& Bauer, 1978; Brethauer \& Paxton, 1977; Pueppke et al., 1980). Transmission and scanning electron microscopy suggested that $R$. japonicum interacted specifically with root hairs of its soybean host through SBL-binding surface polysaccharides (Bal et al., 1978; Stacey et al., 1980). Polysaccharide receptors for SBL have been described as O-antigen-containing lipopolysaccharides (Wolpert \& Albersheim, 1976), capsular polysaccharides (Bal et al., 1978; Mort \& Bauer, 1980; Tsien \& Schmidt, 1980, 1981), and exocellular diffusible material (Bhuvaneswari et al., 1977; Brethauer \& Paxton, 1977; Kamberger, 1979; Mort \& Bauer, 1980, 1982; Pueppke et al., 1980; Tsien \& Schmidt, 1980, 1981). The degree of binding of SBL to $R$. japonicum also varied among strains (Bhuvaneswari \& Bauer, 1978; Bhuvaneswari et al., 1977; Bohlool \& Schmidt, 1974; Calvert et al., 1978), and cells of some strains bound SBL only when cultured in

\footnotetext{
Abbreviations: G/RR/UA, glutaraldehyde/ruthenium red/uranyl acetate; PBS, phosphate buffered saline containing $10 \mathrm{~mm}-\mathrm{KH}_{2} \mathrm{PO}_{4} / \mathrm{K}_{2} \mathrm{HPO}_{4}, 145 \mathrm{mM}-\mathrm{NaCl}, 1 \mathrm{mM}-\mathrm{MgSO}_{4}, \mathrm{pH} 7.0 ; \mathrm{SBL}$, soybean lectin; TEM, transmission electron microscopy.
} 
the root environment (Bhuvaneswari \& Bauer, 1978) or during certain phases of growth (Bhuvaneswari et al., 1977; Mort \& Bauer, 1980). For two reference strains of $R$. japonicum (3I1 B 110 and 311 B 138), the growth phase-dependent variations have been attributed to changes in the composition of capsular and extracellular polysaccharides and to the loss of encapsulation during batch culture (Mort \& Bauer, 1980). Other studies of $R$. japonicum 3IlB138 growing in broth reported that SBL-binding material was not restricted to certain stages of growth, but rather was synthesized in synchrony with cell division throughout the growth cycle (Tsien \& Schmidt, 1980, 1981).

In the studies which examined the binding of SBL to broth-grown $R$. japonicum by electron microscopy (Bal et al., 1978; Calvert et al., 1978; Shantharam et al., 1980; Stacey et al., 1980; Tsien \& Schmidt, 1981), the cells were subjected to centrifugation, which may have introduced artifacts by shearing the capsular polysaccharides. Therefore, we have re-examined the development and lectin-binding properties of the capsule of $R$. japonicum 311 B 110 using a new method of specimen preparation for transmission electron microscopy (TEM) (Mutaftschiev et al., 1982). Using this method, cells were not centrifuged or dehydrated. In this way, the development of capsules and lectin-binding sites could be more accurately assessed. A preliminary report of this work was presented at the 82nd Annual Meeting of the American Society for Microbiology (Truchet et al., 1982).

\section{METHODS}

Bacterial culture. Rhizobium japonicum $311 \mathrm{~B} 110$, from $\mathrm{Dr}$ D. Weber, USDA, Beltsville, Md., USA, was grown aerobically in shaken cultures of YMS broth (Tsien \& Schmidt, 1980) at $30^{\circ} \mathrm{C}$. Cells in mid-exponential phase were used as the inoculum ( $1 \mathrm{ml}$ of a suspension of $\mathrm{OD}_{620}=1.0$ per $100 \mathrm{ml}$ broth). Culture growth was measured by optical density at $620 \mathrm{~nm}$ through a $1 \mathrm{~cm}$ cuvette. When necessary, samples were diluted with sterile broth to less than 0.3 OD unit.

Lectins. SBL isolated by affinity chromatography from Glycine max (L.) Merr. cv. Portage seeds was a gift of S. G. Pueppke, University of Florida, USA. In addition, SBL and Lens lentil lectin were purchased from Miles Laboratories, Elkhart, Ind., USA.

Conjugation of SBL to colloidal gold. Colloidal gold was prepared according to Frens (1973) from an aqueous solution of trichloroauric acid (Polysciences Inc., Warrington, Pa., USA). The average diameter of the gold particles was $16 \mathrm{~nm}$. The lowest concentration of SBL required to stabilize the colloidal gold was determined visually (Horisberger et al., 1975). The stabilized gold colloid was free of aggregates as judged by TEM (figure not shown). SBL was conjugated with colloidal gold (Horisberger et al., 1975) except that the SBL and freshly prepared colloidal gold suspension were mixed for $15 \mathrm{~min}$ with constant stirring before centrifugation for $45 \mathrm{~min}$ at $30000 \mathrm{~g}$. The pellet from $10 \mathrm{ml}$ of the conjugated colloid was resuspended gently on ice in $2 \mathrm{ml} 1 \%(\mathrm{w} / \mathrm{v})$ polyethylene glycol (av. mol. wt 20000) in PBS ( $\mathrm{pH} 7.0)$, preserved with sodium azide $(0.02 \%, \mathrm{w} / \mathrm{v}$ final concentration), and stored at $4{ }^{\circ} \mathrm{C}$.

TEM of whole bacteria. To localize exocellular acidic polysaccharides, cells in broth culture were examined directly by the glutaraldehyde/ruthenium red/uranyl acetate (G/RR/UA) method (Mutaftschiev et al., 1982). Briefly, this involved deposition of $3 \mu \mathrm{l}$ of an uncentrifuged bacterial suspension onto a carbon-coated Formvar grid, adsorption of the cells for $3 \mathrm{~min}$, and subsequent removal of the free-standing suspension by blotting with filter paper. Adsorbed cells were stained with a mixture of glutaraldehyde and ruthenium red, and then contrasted with uranyl acetate. In some cases, $3 \mu$ broth culture was deposited on grids and evaporated at room temperature before staining. Grids were then examined by TEM with a Hitachi H600 electron microscope at $75 \mathrm{kV}$.

To localize anionic sites by cationized ferritin, the labelling procedure described by Schrevel et al. (1981) was adapted to study whole bacteria. Equal volumes of bacterial broth culture and $0.5 \%(\mathrm{v} / \mathrm{v})$ glutaraldehyde in $0.2 \mathrm{M}$ sodium cacodylate buffer (pH 7.2) were mixed. Two $\mu$ l of this mixed solution was deposited on a Formvar-coated grid and gently dried under a stream of sterile air. The dried grid was floated on a drop of sterile cationized ferritin $\left(85 \mu \mathrm{gl}^{-1}\right)$ in sodium veronal buffer (0.1 $\mathrm{M}, \mathrm{pH} \mathrm{7.2)}$. After incubation for $1 \mathrm{~min}$, the remaining solution was blotted with filter paper. Non-specific binding of cationized ferritin was removed by five washes of Veronal buffer for 10 min each without blotting between each wash. After the last rinse, the grid was blotted with filter paper and completely dried under sterile air. Controls were incubated with a sterile solution of native ferritin (Sigma) under the same conditions.

To localize SBL-binding sites, bacteria adsorbed to grids were treated under sterile conditions at room temperature with SBL-colloidal gold for $10 \mathrm{~min}$ in a humid chamber. After blotting off the excess SBL-gold, the adsorbed cells were washed with PBS for $10 \mathrm{~min}$ and finally stained by the G/RR/UA method. Other grids were incubated with SBL-gold and then washed three times with PBS without staining by G/RR/UA. For controls, 
bacteria on grids were incubated with the same stock of unconjugated colloidal gold or with a lentil lectin-gold complex prepared as described above. Cells were then stained by the G/RR/UA method.

To study hapten reversibility of lectin binding, cells on grids which had been treated with lectin-gold complexes were incubated for $3 \mathrm{~min}$ in humid air at room temperature with 10,25 and $50 \mathrm{mM}$ solutions of either $N$-acetyl-Dgalactosamine (Lis $e$ al., 1970), $N$-acetyl-D-glucosamine or 2-deoxy-D-glucose. Afterwards, cells were stained by the G/RR/UA method.

To examine bacterial agglutination, $5 \mu$ l of a broth culture were incubated with $5 \mu$ SBL-gold in sterile conditions at room temperature. After $15 \mathrm{~min}, 2 \mu 1$ of the mixture were deposited on Formvar-coated grids, blotted, and the cells stained by the G/RR/UA method. Controls included bacteria treated with PBS or uncoupled colloidal gold in place of SBL-gold, followed by staining by the G/RR/UA method.

\section{RESULTS}

The morphology and size of the capsule on $R$. japonicum 3 IIB 110 changed gradually with culture age. In early exponential phase, the capsule began to develop at one cell pole as a very compact structure which became electron-dense following ruthenium red staining (Fig. 1a,b). At mid-exponential phase, the capsule was a well-developed structure and extended as far as $3 \mathrm{\mu m}$ from the cell wall (Fig. $1 c, d$ ). In late exponential and early stationary phases, the capsule had less-defined borders and dispersed into the culture medium, showing a typical 'radiating' appearance on the Formvar surface (Fig. $1 e, f$ ). The shedding of polymers in stationary phase was accompanied by a progressive decrease of capsule size. However, capsules were still detected at one pole of some cells after $16 \mathrm{~d}$ incubation. At all growth phases, the capsule was exclusively located at one cell pole regardless of how the cells were treated on the grids, i.e. after blotting with filter paper or drying with a gentle stream of air. This result indicated that blotting the specimen on the grid did not affect the distribution of capsular material associated with the cells.

In early exponential phase, the capsule was composed of aggregated, electron-dense and ruthenium red-positive material in close contact with the cell surface (Fig. $1 b$ ). In older cultures, this aggregated material extended further out from the pole and was interconnected with an ultrastructurally different fibrillar material which also reacted with ruthenium red (Fig. Id). The acidic nature of these two polymers, as suggested by their affinity for ruthenium red (Fig. $1 b-f$ ), was confirmed at all growth phases by the extensive binding of cationic ferritin to the polar capsule (Fig. 2a,b).

During early exponential phase, the uncentrifuged cell-free culture medium was typically devoid of electron-dense material (Fig. $1 a$ ). Beginning in mid-exponential phase, extracellular amorphous aggregates and loose fibrils were found concurrently with the dispersion of the capsule (Fig. le, $f$ ). These extracellular materials resembled the polymers of the capsule and were particularly abundant in the medium of stationary phase cultures.

The percentage of polarly encapsulated cells changed with culture age (Fig. 3). The highest percentage $(68 \%)$ of encapsulated cells as exemplified in Fig. $1(b, d)$ occurred at day 3 in an exponential phase which lasted from day 2 to day 5 . Later, this percentage declined to $20 \%$ at day 12 in late stationary phase (Fig. 3).

Low-speed centrifugation $(3000 \mathrm{~g}$ for $30 \mathrm{~min}$ ) separated broth cultures into a hard pellet, an overlying soft pellet and a clear supernatant. The volume of these three fractions changed with culture age. Examination of these fractions by the G/RR/UA method revealed that the hard pellet contained predominantly non-encapsulated cells (Fig. $4 a$ ), the soft pellet contained predominantly polarly encapsulated cells (Fig. $4 b$ ), and the supernatant contained both capsular polymers which were more abundant in older cultures (Fig. 4 c).

The polar aggregated material on uncentrifuged cells in early exponential phase intensively bound SBL-colloidal gold (Fig. $5 a$ ). Later, in mid- and late exponential phases, SBL receptors exclusively matched the location of the enlarged polar capsule (Fig. $5 b$ ). However, the SBLcolloidal gold did not bind to the naked cell surface, the flagellum, or the fibrillar material of the outer capsule, regardless of the growth phase (Fig. $5 a-c$ ).

As the percentage of encapsulation decreased with culture age (Fig. 3), there was a progressive increase of SBL-binding material in the surrounding medium, indicating that shedding had 
(a)

(c)

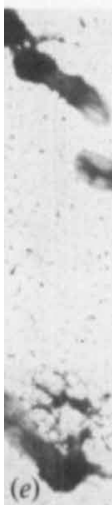

(d)

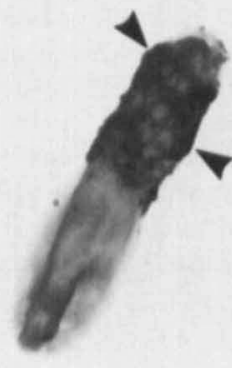

(b)

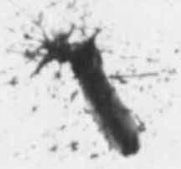

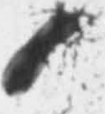
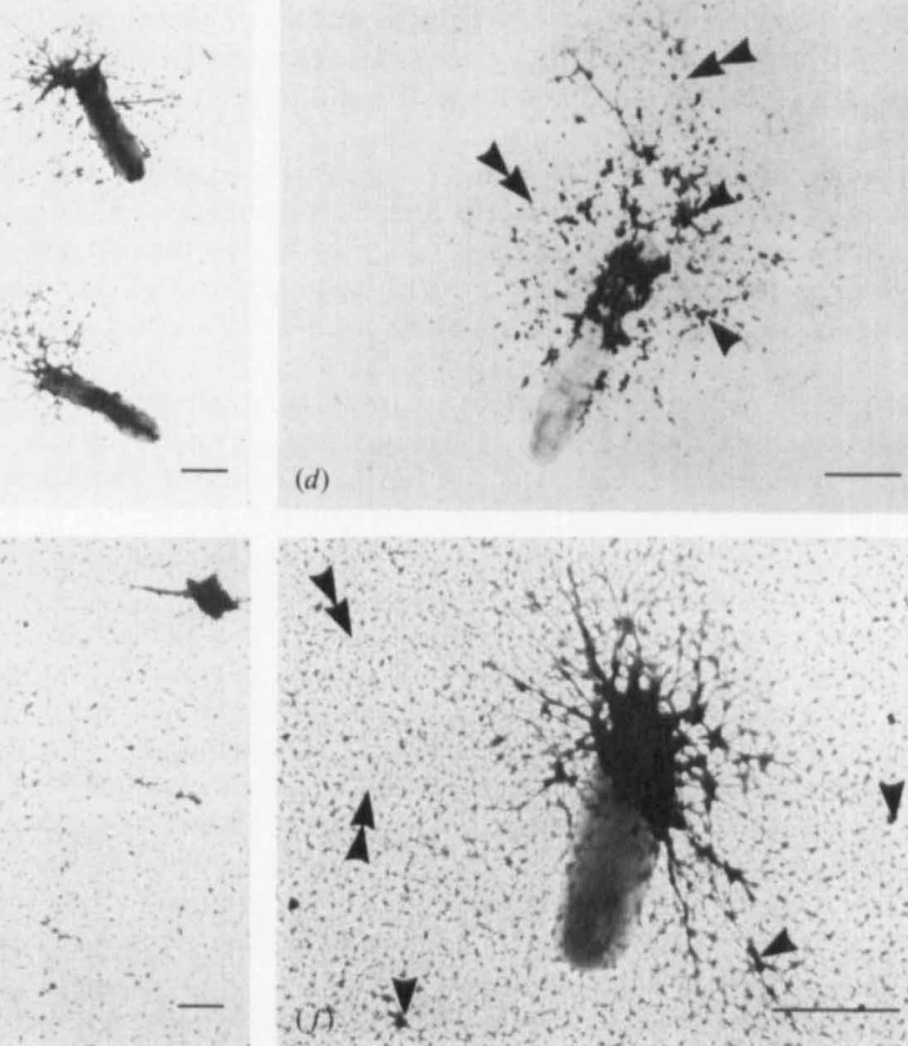

Fig. 1. Rhizobium japonicum $311 \mathrm{~B} 110$ stained by G/RR/UA showing the progressive steps of encapsulation. $(a, b)$ Early exponential phase: $(a)$ the beginning of the capsule; $(b)$ the nascent capsule (arrows) is seen as an aggregated material in close contact with one pole of the cell. (c, $d$ ) Midexponential phase: (c) well-developed capsule; $(d)$ detail of a polar capsule showing the aggregated (single arrows) and the fibrillar (double arrows) components. ( $e, f$ Late stationary phase: (e) accumulation of material in the medium concurrent with the shedding of the capsule; $(\delta)$ both the aggregated (single arrows) and the fibrillar (double arrows) components of the capsule were shed into the medium. In all these and subsequent micrographs, bar markers represent $1 \mu \mathrm{m}$.

occurred (Fig. $5 c, d$ ). Consistent with the above results, the cell-free SBL receptors were associated with the aggregated rather than the fibrillar type polymer (Fig. 5e). 


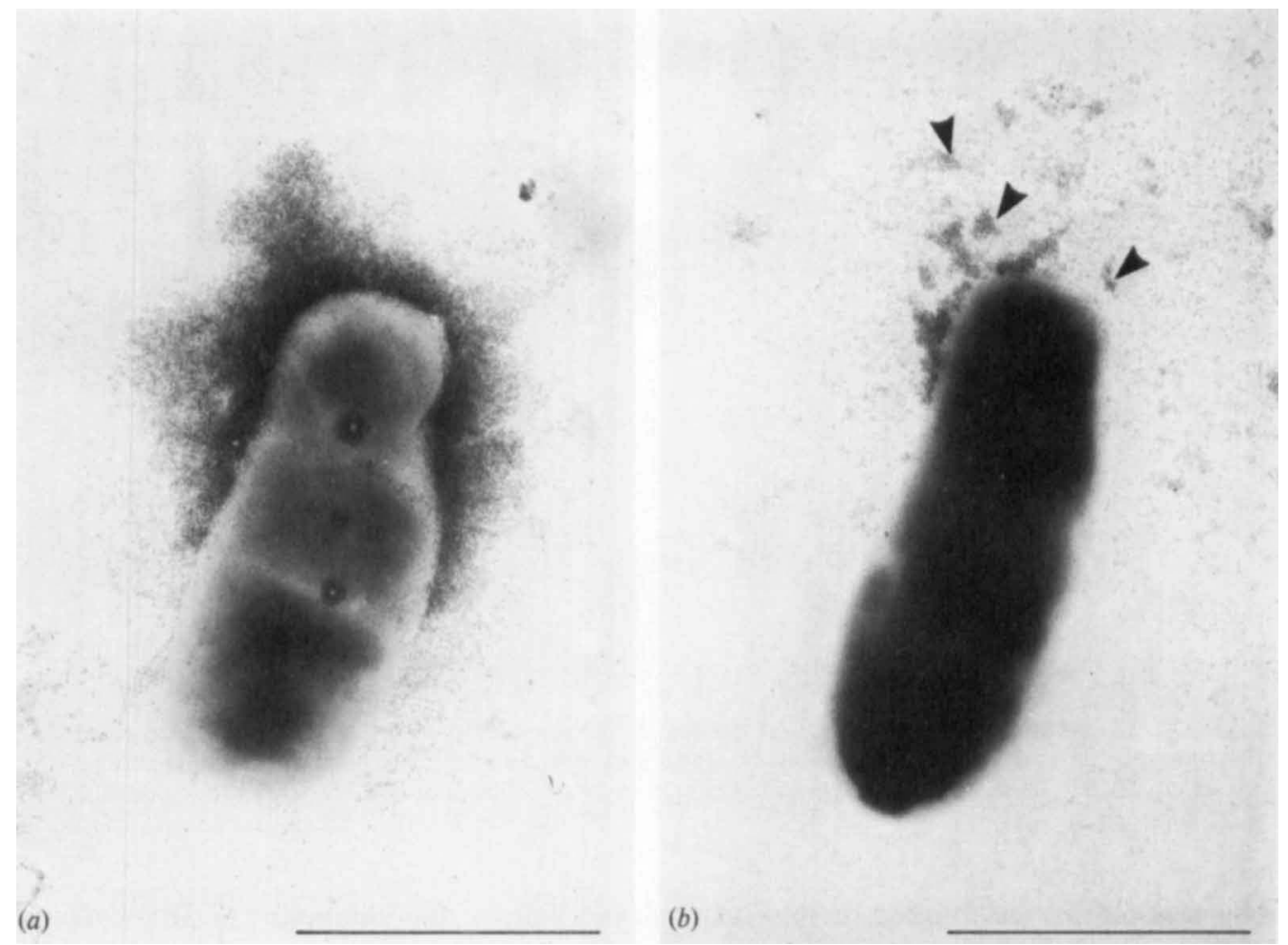

Fig. 2. Localization of anionic sites by cationic ferritin. (a) Early exponential phase: cationic ferritin is densely accumulated at one pole of the cell. (b) Mid-exponential phase: the distribution of ferritin particles matches the spatial distribution of the capsule. The dense deposition of ferritin probably corresponds to the aggregated capsular component (arrows).

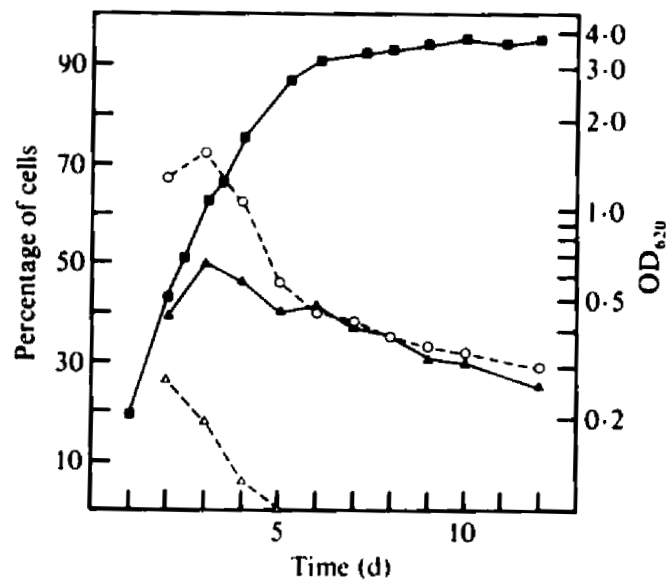

Fig. 3. Lectin-binding activity and encapsulation of $R$. japonicum $311 \mathrm{~B} \mid 10$ during the first $12 \mathrm{~d}$ of growth in YMS broth. G. Growth curve $\left(\mathrm{OD}_{020}\right) ; O$, percentage of lectin-binding cells. At each day of growth, the total percentage of encapsulated cells included both the percentage of cells with a welldeveloped $(\Delta)$ and nascent $(\Delta)$ capsule. 

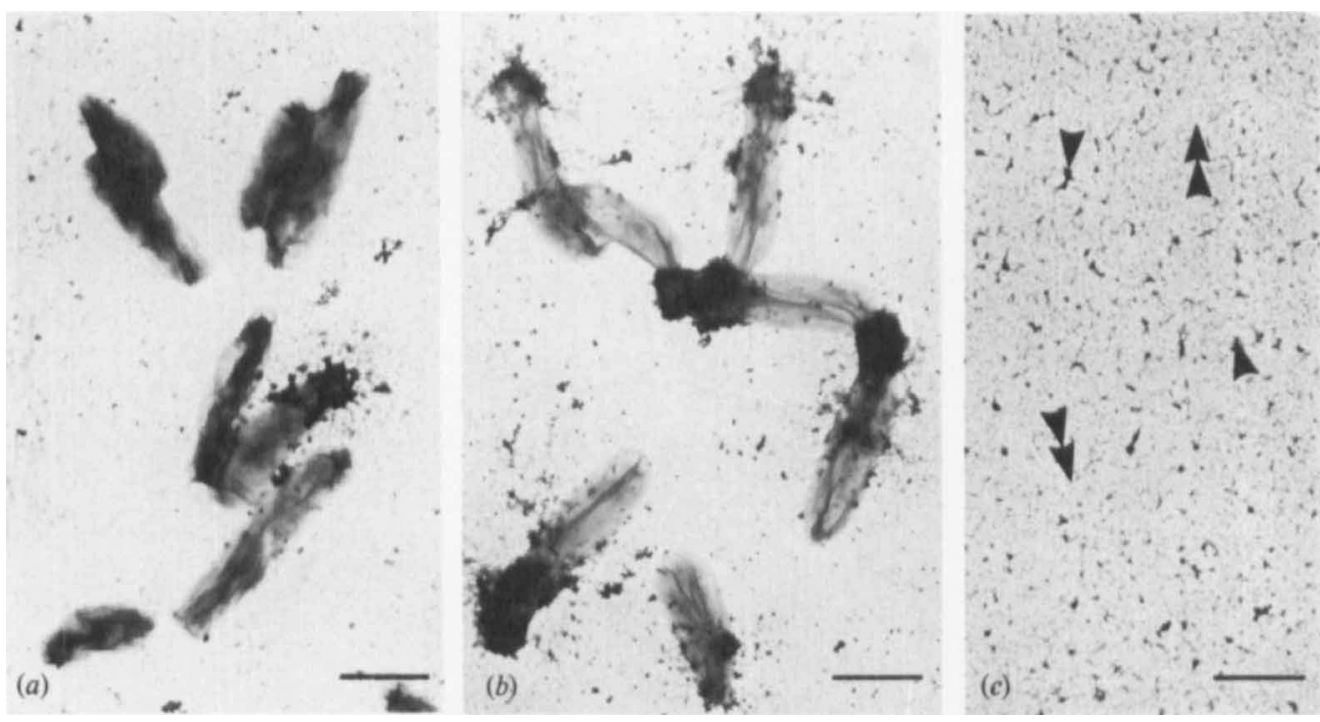

Fig. 4. Different centrifuged fractions of a 6-day-old culture stained with G/RR/UA. (a) Hard pellet containing the majority of unencapsulated cells; $(b)$ soft pellet enriched with polarly encapsulated cells; (c) supernatant containing both aggregated (single arrows) and fibrillar (double arrows) components.

Several controls established the biochemical specificity of the interaction of SBL-colloidal gold with the cell-bound and cell-free aggregated polymer. $N$-Acetyl-D-galactosamine, a specific hapten of SBL, reversed the interaction at a concentration of $10 \mathrm{mM}$ (Fig. $6 a, b$ ). No hapten reversal was obtained with the non-inhibitory analogues $N$-acetyl-D-glucosamine or 2-deoxy-Dglucose at even $50 \mathrm{mM}$ (Fig. 6c). Uncoupled colloidal gold or lentil lectin-gold complex did not bind to the bacteria or extracellular materials (figures not shown). Cells incubated with SBLcolloidal gold without further treatment had lectin bound predominantly to one pole, presumably where the aggregated polymers of the capsule were located (Fig. 7a,b). The few SBL-gold particles on the opposite pole of the cell (Fig. $7 a$ ) were easily removed by subsequent washing with PBS or treatment by the G/RR/UA method, indicating that they were not bound to the cell surface in a biochemically specific manner. This control also indicated that treatment of cells by the G/RR/UA method did not redistribute the SBL-binding receptors on the capsule. The same treatment showed that the cell-free aggregated polymer, but not the cell-free fibrillar polymer, was able to bind the SBL-gold complex (Fig. 7c).

The percentage of cells which bound SBL was maximal at day 3 and then progressively decreased during growth (Fig. 3). At each growth phase, the percentage of SBL-binding cells changed in parallel with the percentage of encapsulated cells (Fig. 3). Encapsulated cells in late stationary phase (up to day 16) were still able to bind SBL in a hapten-reversible way (Fig. 8).

Consistent with previous studies (Truchet et al., 1983), the G/RR/UA method revealed that $\boldsymbol{R}$. japonicum could be agglutinated by SBL-gold (Fig. 9). Bacteria incubated with PBS or uncoupled colloidal gold did not agglutinate (figures not shown).

\section{DISCUSSION}

The G/RR/UA method has been applied here to study the capsule development and the lectin-binding properties of $R$. japonicum 3I1B 110 . The capsule of this slow-growing strain developed at one pole and remained exclusively at this cellular location regardless of the phase of growth. Ultrastructurally, it consisted of two materials which stained with ruthenium red and bound cationic ferritin, but differed in electron density, morphology, location within the capsule, and reactivity with soybean lectin. The electron-dense aggregated material bound SBL 

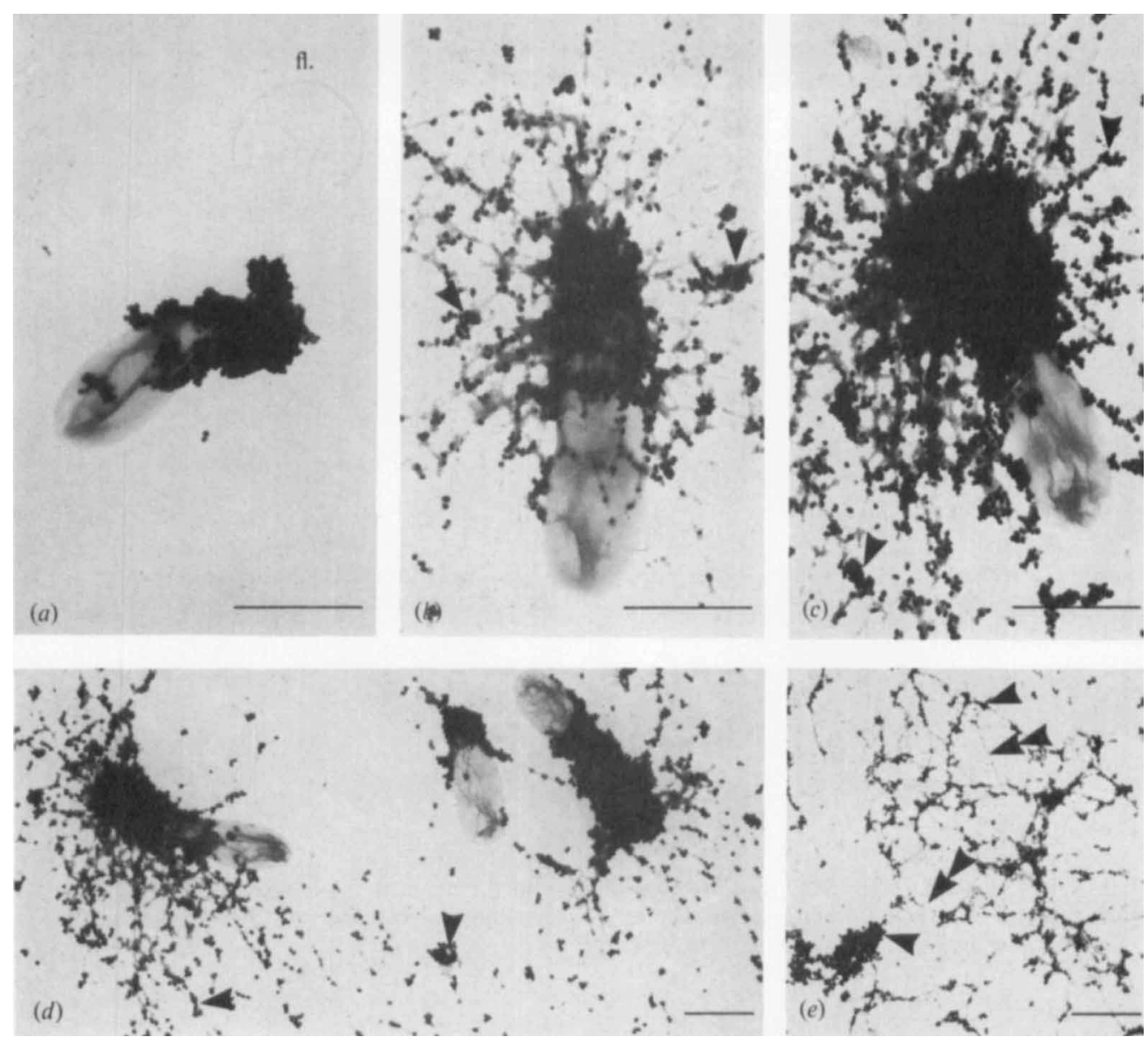

Fig. 5. Treatment of cells with SBL-colloidal gold followed by staining with G/RR/UA. SBL-colloidal gold bound to the capsule of bacteria collected in early $(a)$, mid- $(b)$ and late $(c, d)$ exponential phase. SBL-colloidal gold bound to the aggregated materials (arrows) of well-developed $(b)$ or diffusing $(c, d)$ capsules, but not to the naked cell surface $(a-d)$ or to the flagellum $(a, f$.$) . (e) Extracellular material of a$ 6-day-old culture (early stationary phase). SBL-colloidal gold was exclusively bound to the aggregated component (single arrows). The double arrows indicate the fibrillar component which did not bind SBL-gold.

in a biochemically specific manner and represented the capsular material retained at the 'cytoplasmic and nuclear pole' of thin-sectioned and freeze-etched bacteria (Calvert et al., 1978; Tsien \& Schmidt, 1977), and the 'very high molecular weight form' of the capsule which was isolated by ultracentrifugation at $100000 \mathrm{~g}$ (Tsien \& Schmidt, 1981). In contrast, the fibrillar material which did not bind SBL-gold was probably lost during specimen preparation in other studies as suspected (Tsien \& Schmidt, 1981). Both of these capsular polymers were shed into the culture medium as the culture aged and retained their differential hapten-specific reactivity with SBL. A relationship between the capsular polysaccharide and exocellular acidic polysaccharides was also suggested by their chemical similarity (Mort \& Bauer, 1980, 1982), although exopolysaccharides tended to be more polydisperse in molecular weight (Tsien \& Schmidt, 1981; I. Sutherland, personal communication).

The polar capsule as described here seemed to be a general feature of most slow-growing rhizobia which develop capsules (Vasse, 1982; J. M. Vasse \& G. L. Truchet, unpublished observations). The appearance of a capsule completely surrounding the $R$. japonicum cell in thin 


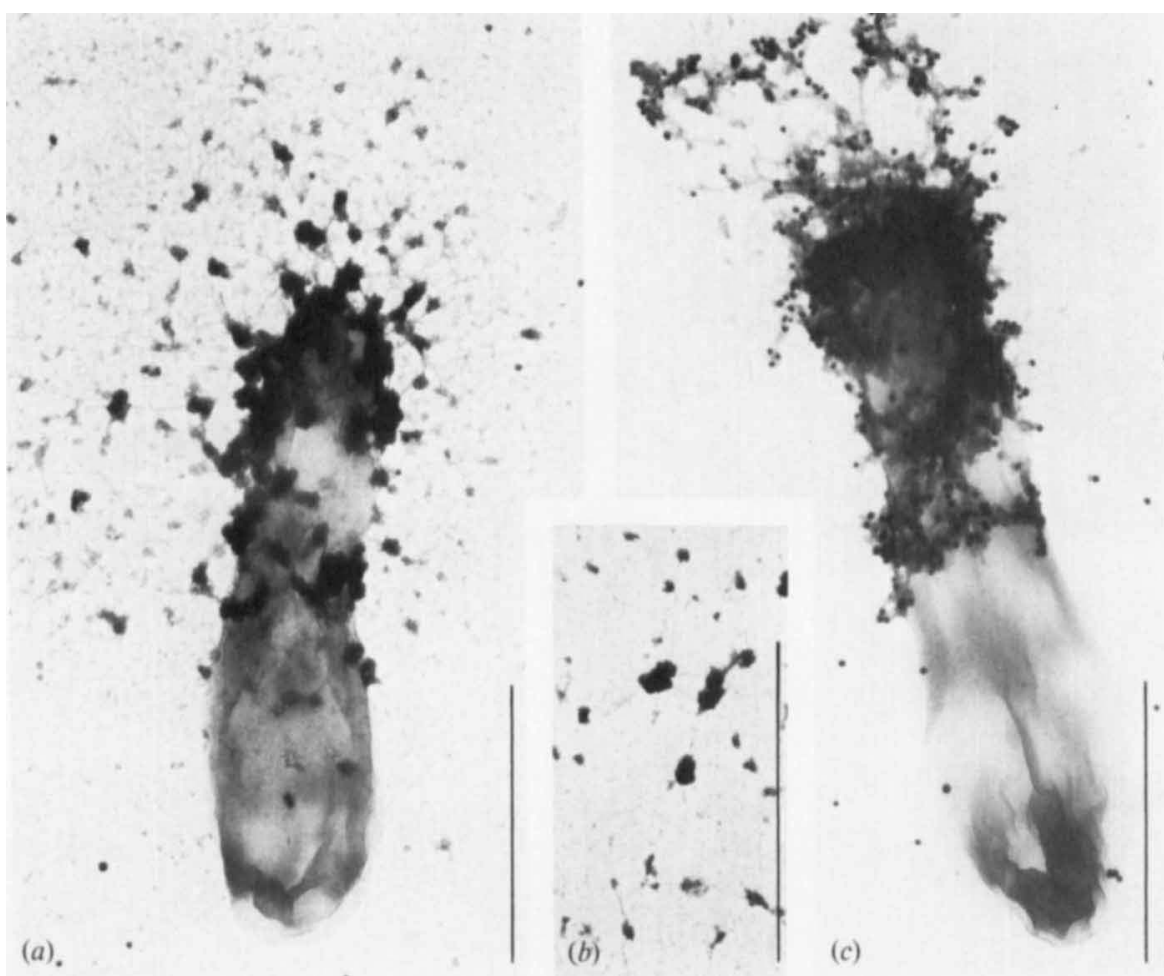

Fig. 6. Reversion of the SBL-colloidal gold binding to the capsular (a) or the extracellular (b) materials with $10 \mathrm{mM}-N$-acetyl-D-galactosamine. No reversion was observed with $50 \mathrm{mM}-N$-acetyl-Dglucosamine $(c)$.
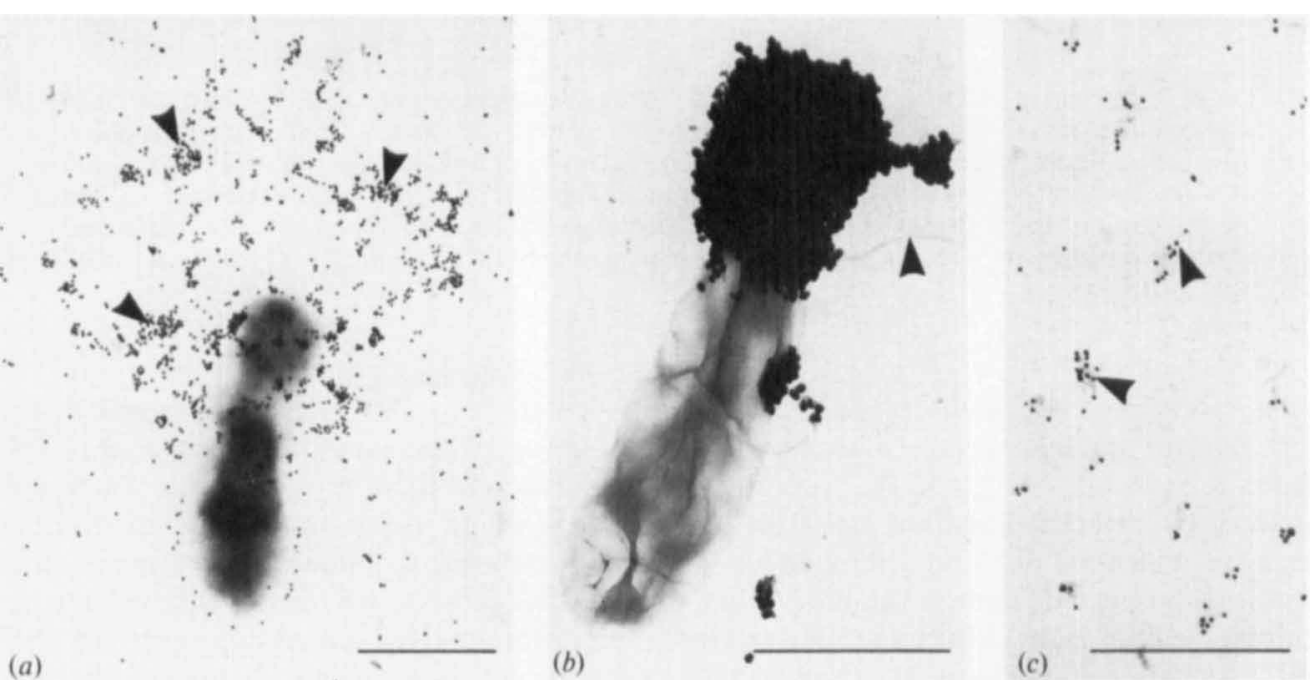

Fig. 7. Treatment by SBL-colloidal gold without subsequent washings ( $a$ ) or followed by washings with uranyl acetate (b) or PBS (c). (a) Cell in mid-exponential phase. The distribution of lectin receptors, particularly concentrated in certain places of the capsule (arrows), probably corresponds to the spatial distribution of the aggregated component. The few SBL-gold particles at the opposite pole could easily be removed by subsequent washings. (b) Cell in early exponential phase. SBL-colloidal gold intensively bound to the nascent polar capsule but not to the flagellum (arrow) or to the cell itself. (c) SBLcolloidal gold bound to the extracellular aggregated material (arrows) of cells in early stationary phase. 


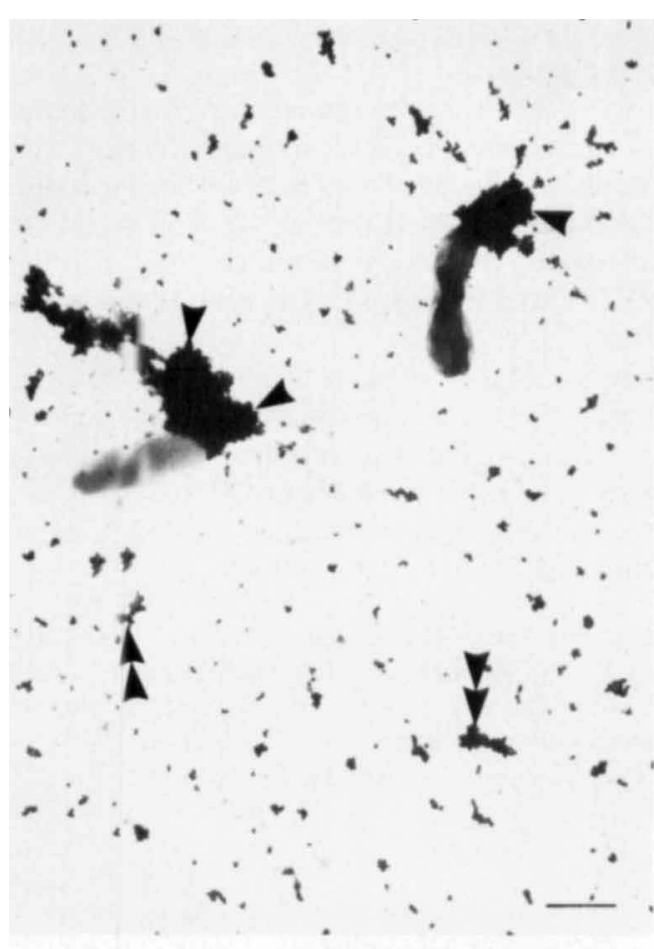

Fig. 8

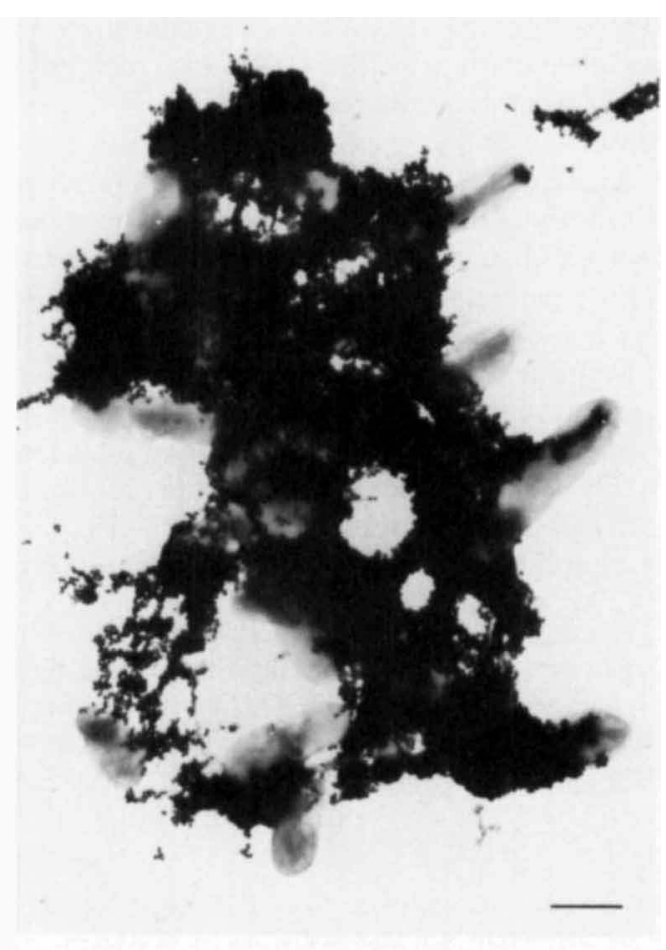

Fig. 9

Fig. 8. Treatment of cells in late stationary phase (16-day-old culture) with SBL-colloidal gold followed by staining with G/RR/UA. SBL-gold bound to the capsule (single arrows) and to the extracellular material (double arrows).

Fig. 9. SBL-colloidal gold mediated agglutination of a 4-day-old culture.

sections (Bal et al., 1978; Calvert et al., 1978: Shantharam et al., 1980) or in negative stains using India ink (Mort \& Bauer, 1980) may be due to the orientation of the thin-section which did not encompass the entire length of the cell or to a redistribution of capsular materials during centrifugation or other steps of specimen preparation. This hypothesis was supported by the observation that cells from 9-day-old uncentrifuged cultures had polar capsules when examined by the G/RR/UA method but were unencapsulated when processed for thin-sectioning (figure not shown).

Our results are in general agreement with other studies showing that SBL receptors were located on the capsule and not on unencapsulated cell surfaces of $\boldsymbol{R}$. japonicum growing in broth culture (Bal et al., 1978; Calvert et al., 1978; Mort \& Bauer, 1980; Shantharam et al., 1980; Stacey et al., 1980; Tsien \& Schmidt, 1981). In addition, the results confirmed that the percentage of cell encapsulation and SBL-binding ability of broth cultures reached their maxima in mid-exponential phase and both declined thereafter. Thus, the overall agreement of our results with previous studies attested to the validity of this new method. Its main advantage in comparison with others is that it optimizes the relationship of encapsulation and binding of lectin with a minimum of loss due to specimen handling. This was illustrated by the failure of India ink exclusion techniques (Mort \& Bauer, 1980) and fluorescence microscopy (Bhuvaneswari et al., 1977: Mort \& Bauer, 1980; Truchet et al., 1983) to detect encapsulated cells of $R$. japonicum $311 \mathrm{~B} 110$ in late stationary phase which were still able to bind SBL specifically. This positive result obtained by the G/RR/UA method was not an artifact created by deposition of extracellular material on the grid since its location was exclusively polar rather than random on cells. The complication of accumulated extracellular material obscuring the 
observations in older cultures was minimized by preventing the grids from drying until the entire sequence of steps of the G/RR/UA method was completed.

The progressive increase of lectin-binding material in the culture medium concurrent with the capsule dispersion explains why the culture as a whole retained its SBL-binding activity (Tsien \& Schmidt, 1980). The methylation of galactose residues has been shown to result in a decrease in affinity of SBL for the bacterial polymer (Mort \& Bauer, 1980). However, we were unable to detect a change in affinity of SBL-gold for the aggregated capsular material on cells or in the culture medium at all growth phases based on a differential inhibition by $\boldsymbol{N}$-acetyl-D-galactosamine within the concentration range of $10-50 \mathrm{mM}$.

Schmidt \& Bohlool (1981) suggested that different methods used in different laboratories could account for contradictory results and proposed the use of common procedures among workers. Because the G/RR/UA method is simple and allows the observation of entire bacteria by TEM, it could be of value to study mutant strains of rhizobia (Law et al., 1982; Rolfe et al., 1981) and clarify the morphological basis of recognition events mediated by lectin-polysaccharide interactions in this nitrogen-fixing symbiosis.

This work was supported by grants to F. B. D. from the National Science Foundation (PCM 80-21906), the US Department of Agriculture Competitive Research Grant 82-CRCR-1-1040 and the Michigan Agricultural Experiment Station Project 1314H (Journal Article no. 10354), and to G. L. T. from Elf Aquitaine, l'Entreprise Minière et Chimique, CDF. Chimie et Rhône-Poulenc Recherches. We thank Steve Pueppke for supplying affinity-purified soybean lectin, and Estelle Hrabak and John Sherwood for helpful suggestions.

\section{REFERENCES}

Bal, A. K., Shantharam, S. \& Ratnam, S. (1978). Ultrastructure of Rhizobium japonicum in relation to its attachment to root hairs. Journal of Bacteriology 133. 1393-1400.

BhuVANeswari, T. V. \& BAUER, W. D. (1978). The role of lectins in plant-microorganism interactions. IIl. Influence of rhizosphere/rhizoplane culture conditions on the soybean lectin-binding properties of rhizobia. Plant Physiology 62, 71-74.

Bhuvaneswari, T. V., Puepree, S. G. Bauer, W. D. (1977). Role of lectins in plant-microorganism interactions. I. Binding of soybean lectin to thizobia. Plant Physiology 60, 486-491.

BOHLOOL, В. В. SCHMIDT, E. L. (1974). Lectins: a possible basis for specificity in the Rhizobiumlegume root nodule symbiosis. Science 185, 269271.

Brethauer, T. S. \& Paxton, J. D. (1977). The role of lectin in soybean-Rhizobium japonicum interactions. In Cell Wall Biochemistry Related to Specificity in Host-Plant Pathogen Interactions, pp. 381-387. Edited by B. Solheim \& J. Raa. Oslo: Universitetsforlaget.

Calvert, H. E., Lalonde, M., Bhuvaneswari, T. V. \& BAuER, W. D. (1978). Role of lectins in plantmicroorganism interactions. IV. Ultrastructural localization of soybean lectin binding sites on Rhizobium japonicum. Canadian Journal of Microbiology 24, 785-793.

Frens, G. (1973). Controlled nucleation for the regulation of the particle size in monodispersed gold suspensions. Nature, London 241, 20-22.

Horisaerger, M., Rosset, J. \& Bauer, H. (1975). Colloidal gold granules as markers for cell surface receptors in the scanning electron microscope. Experientia 31. 1147-1151.

Kamberger, W. (1979). An Ouchterlony double diffusion study on the interaction between legume lectins and rhizobial cell surface antigens. Archites of Microbiology 121, 83-90.

LAw, I. J., Yamamoto, Y., Mort, A. J. \& Bauer, W. D. (1982). Nodulation of soybean by Rhizobium japonicum mutants with altered capsule synthesis. Planta 154, 100-109.

Lis, H., Sela, B., SAChs, L. \& Sharon, N. (1970). Specific inhibition by $N$-acetyl-D-galactosamine of the interaction between soybean agglutinin and animal cell surfaces. Biochimica ef biophysica acta 211, 582-585.

Mort, A. J. \& Bauer, W. D. (1980). Composition of the capsular and extracellular polysaccharides of Rhizobium japonicum: changes with culture age and correlations with binding of soybean seed lectin to the bacteria. Plant Physiology 66, 158-163.

MORT, A. J. \& BAUER, W. D. (1982). Structure of the capsular and extracellular polysaccharides of Rhizobium japonicum that bind soybean lectin. Journal of Biological Chemistry 257, 1870-1875.

Mutaftschiev, S., VAsse, J. \& TRUChet, G. L. (1982). Exostructures of Rhizobium meliloti. FEMS Microbiology Letters 13, 171-175.

Pueppke, S. G., Freund, T. G., Schultz, B. C. \& Friedman, H. P. (1980). Interaction of lectins from soybean and peanut with rhizobia that nodulate soybean, peanut, or both plants. Canadian Journal of Microbiology 26, 1489- 1497.

Rolfe, B. G., DJORdJeVIC, M., SCOTt, K. F., HUGHes, J. E., BADENOCH-JoNes, J., GREsShoff, P. M., CEN, Y., Dudman, W. F., Zurkowski, W. \& Shine, J. (1981). Analysis of the nodule forming ability of fastgrowing Rhizobium strains. In Current Perspectives in Nitrogen Fixation, pp. 142-145. Edited by A. H. Gibson W. E. Newton. Canberra: Australian Academy of Science.

SCHMIDT, E. L. \& BOHLOOL, B. B. (1981). The role of lectins in symbiotic plant-microbe interactions. In 
Encyclopedia of Plant Physiology, New'Series, vol. 138, pp. 658-677. Edited by W. Tanner \& F. A Loewus. Berlin, Heidelberg: Springer-Verlag.

Schrevel, J., Gros, D. \& Monsigny, M. (1981). Cytochemistry of cell glycoconjugates. In Progress in Histochemistry and Cytochemistry, vol. 14, 2, pp. 79 . 87. Edited by W. Graumann, Z. Lojda, A. G. E. Pearse 2 T. H. Schiebler. Stultgart, New York: Gustav Fischer Verlag.

Shantharam, S., Gow, J. A. \& Bal, A. K. (1980). Fractionation and characterization of two morphologically distinct types of cells in Rhizobium japonicum broth culture. Canadian Journal of Microbiology 26, 107-114.

Stacey, G., PauU, A. G. \& Brill, W. J. (1980). Host recognition in the Rhizobium-soybean symbiosis. Plant Physiology 66, 609-614.

Truchet, G. L., Vasse, J. M., Dazzo, F. B. \& PueppKe, S. G. (1982). Transient appearance of soybean lectin receptors on Rhizobium japonicum 311BI10. In Abstracts of the Annual Meeting of the American Society for Microbiology, p. 149. Edited by R. A. Finkelstein \& F. C. Neidhardt. Washington, DC : American Society for Microbiology.
Truchet, G. L., DAzzo, F. B. \& VAsse, J. M. (1983). Agglutination of Rhizobium japonicum $311 \mathrm{~B} 110$ by soybean lectin. Plant and Soil 75, 265-268.

TsIEN, H. C. \& SCrumd, E. L. (1977). Polarity in the exponential-phase Rhizobium japonicum cell. Canadian Journal of Microbiology 23, 1274-1284.

TSIEN, H. C. \& SCHMIDT, E. L. (1980). Accumulation of soybean-lectin binding polysaccharide during the growth of Rhizobium japonicum as determined by hemagglutination inhibition assay. Applied and Environmental Microbiology 39, 1100-1104.

TSIEN, H. C. \& SCHMIDT, E. L. (1981). Localization and partial characterization of soybean lectin binding polysaccharide of Rhizobium japonicum. Journal of Bacteriology 145, 1063-1074.

VASSE, J. M. (1982). Etude des structures exocellulaires chez les bactéries du genre Rhizobium. Thèse de spécialité, Faculté des Sciences Marseille-Luminy. Marseille, France.

WOLPERT, J. \& AlbersheIM, P. (1976). Host-symbiont interactions. 1 . The lectins of legumes interact with the O-antigen-containing lipopolysaccharides of their symbiont rhizobia. Biochemical and Biophysical Research Communications 70, 729-737. 